\title{
Recurrent attack of rotavirus gastroenteritis after adenovirus-induced diarrhoea
}

\author{
S. CHIBA, R. KOGASAKA, M. AKIHARA, K. HORINO, AND T. NAKAO \\ Department of Paediatrics, Sapporo Medical College
}

SUMMARY A 14-month-old baby boy suffered a second attack of rotavirus gastroenteritis within one month of the initial one. The second attack followed a diarrhoeal episode associated with adenovirus. Gastrointestinal symptoms in the second attack ware more severe than those of the first. The adenovirus-associated enteritis was mild compared with the illness in both episodes of rotavirus infection.

We report an infant in whom a second attack of rotavirus gastroenteritis occurred within a month. The second attack followed a diarrhoeal episode associated with type 7 adenovirus.

\section{Case report}

A 14-month-old baby boy was admitted on 8 February 1977 with typical acute gastroenteritis with diarrhoea, vomiting, anorexia, fever, and dehydration (Table). He received intravenous infusion and dietary treatment, and was discharged when completely recovered on 16 February. On 25
February he was brought to the outpatient clinic with a recurrence of diarrhoea. He had no vomiting or fever at that time and initially his condition improved but he continued to have loose stools. On 4 March he was readmitted with severe watery diarrhoea, frequent vomiting, and fever. Symptoms were more severe than those during the first admission; vomiting lasted for 5 days and diarrhoea for over a week. He was discharged when completely recovered on 19 March.

\section{Laboratory data.}

\section{Electron microscopical examination}

Stool specimens were consecutively collected and stored at $-70^{\circ} \mathrm{C}$. The specimens were prepared for electron microscopy (EM) using the method of Flewett et al. (1974). Numerous rotavirus particles were found in the first and fourth stool specimens which were collected on 8 February and 4 March, but not in the other specimens. In the third specimen, collected on 25 February, a large quantity of adenovirus particles were found but no rotavirus ones. EM examination of the original specimens was

Table Clinical and laboratory data on 3 episodes of diarrhoea in a 14-month-old infant

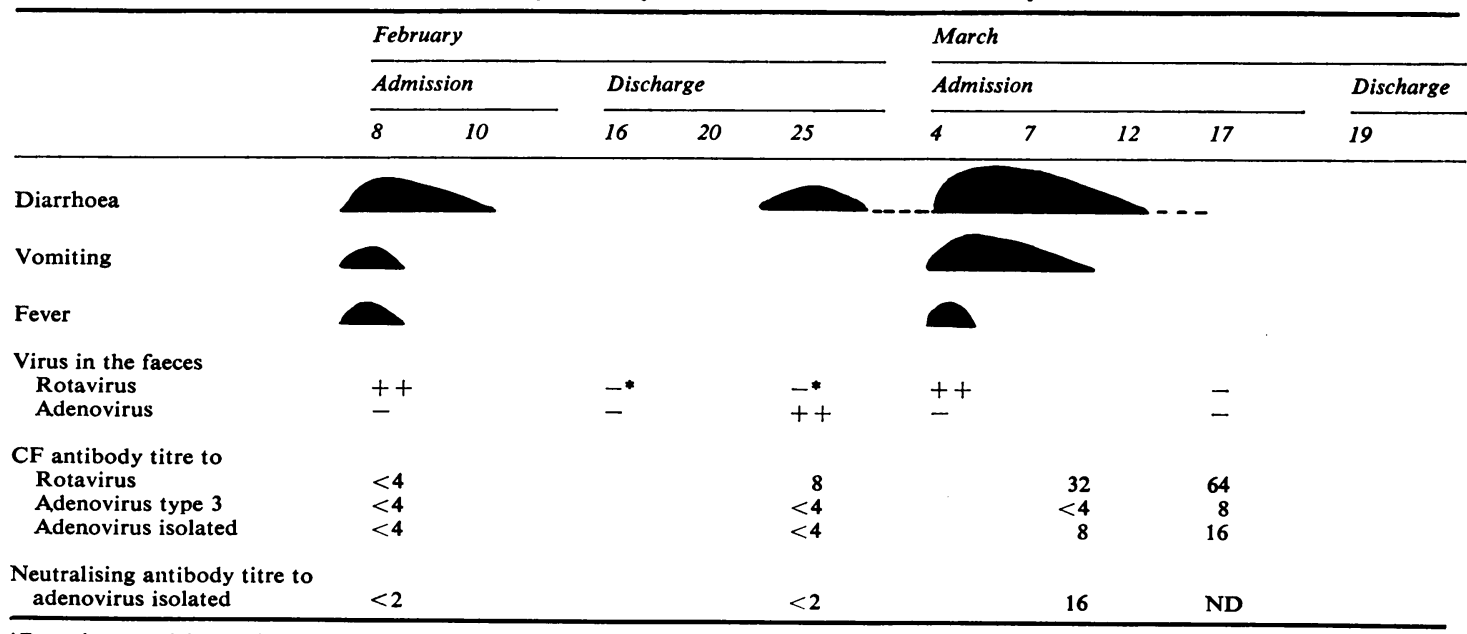

* Rotavirus particles could not be detected by immune electron microscopical examinations. $\mathrm{ND}=$ not done. 
repeated with the same results. Bearing in mind the possibility that a small number of rotavirus particles might be present but not detectable, we also performed immune electron microscopical (IEM) examinations of the second and third specimens: the results were negative.

\section{Culture}

All fresh stool specimens were cultured for bacterial pathogens with negative results. Virus isolation was attempted using primary human embryonic kidney (HEK) cells. A cytopathic agent was recovered from the third stool specimen collected on 25 February. The cytopathic effect was typical of adenovirus, and EM observation of the culture fluid identified the isolate as adenovirus. The isolate was grown in HeLa cells and was identified as type 7 adenovirus.

\section{Serology}

Complement-fixing $(\mathrm{CF})$ antibody titre was measured simultaneously against rotavirus and adenovirus antigens. The human rotavirus antigen was prepared by the method of Bishop et al. (1974) from the virus-rich stools of patients with acute gastroenteritis. Two adenovirus antigens were used; one was prepared from the isolated adenovirus strain and the other from commercially obtained type 3 antigen. CF antibody to rotavirus converted to positive after the first attack and further increased in titre until the last attack of gastroenteritis. Seroconversion to adenovirus antigens was also found during the second and last episodes of diarrhoea, with somewhat higher titres against the isolated virus. Neutralising antibody to the adenovirus isolate was also found to develop concurrently (see Table).

\section{Discussion}

This case may provide valuable information about viral gastroenteritis in view of the reinfection with rotavirus and the apparent pathogenic role of adenovirus in acute diarrhoea.

Although it has been assumed that reinfection with rotavirus could occur with second and subsequent episodes of gastroenteritis or in subclinical form, we are aware of only one patient who had a second episode of rotavirus enteritis (Davidson et al., 1975). That patient, admitted with acute enteritis at 6 and again at 14 months of age, showed rotavirus particles in stools on both occasions. The interval between the attacks of rotavirus-induced gastroenteritis was shorter in our patient. As it is probable that $<10^{5}$ virus particules per $\mathrm{ml}$ would not be detected by routine EM examination, the technique of IEM was used to look for rotavirus during the intervening period. Even with the negative results of IEM, the possibility of an endogeneous reinfection still remained. In that case, adenovirus infection in the intestinal tract might have acted as a trigger for the second invasion of rotavirus. Recent studies have given evidence suggesting the existence of different serotypes among human rotavirus strains (Thouless et al., 1978; Zissis and Lambert, 1978), so it may be possible for the same person to experience reinfection with a different antigenic strain of rotavirus. We could not examine the antigenic variation of rotaviruses recovered from the episodes of gastroenteritis, but it was interesting that gastrointestinal symptoms in the last episode were more severe than those of the first in spite of the pre-existing antibody.

In stools, apart from rotavirus, the second most common group of viruses easily recognisable by EM are adenoviruses (Bruce White and Stancliffe, 1975; Bryden et al., 1975). We have observed adenoviruses in about $5 \%$ of all cases of gastroenteritis occurring in the winter (Kogasaka et al., 1975). An aetiological role of such adenoviruses in gastroenteritis has long been controversial because of the lack of epidemiological evidence. The difficulty of growing in cell culture some adenoviruses which are visible by EM in great numbers contrasts with the easy propagation of some strains of adenoviruses undetectable by EM (Bryden et al., 1975; Madeley et al., 1977). We have used various cell cultures trying to grow adenoviruses visible by EM, and lately found HEK to be the only susceptible cells available in our laboratory. So far, we have grown 5 strains from 7 stool specimens found to be positive by EM, after a few blind passages in HEK (unpublished). One of those strains was recovered from the present patient and it enabled us to test for CF and neutralising antibody responses against the homologous strain. The results showed that primary infection with this type 7 adenovirus was present in the patient. The adenovirus was not just a passenger virus.

The adenovirus-associated enteritis in this case was remarkably mild compared with the illness in both episodes of rotavirus infection. Diarrhoea lasted only a few days and was not accompanied by vomiting. Flewett et al. (1975) reported an outbreak of adenovirus-associated diarrhoea in a long-stay children's ward. They mentioned the mildness of this type of enteritis in comparison with rotavirus enteritis experienced in the same ward. Thus acute enteritis associated with adenoviruses seems to be generally mild. Fatal adenovirus gastroenteritis described by Whitelaw et al. (1977) might be exceptional.

The present case emphasises the need to look for a different pathogen in repeated episodes of gastroenteritis. 


\section{Addendum}

Since this paper was submitted recurrent gastroenteritis associated with different rotavirus serotypes has been reported by Fonteyne et al. (1978) and Rodriguez et al. (1978).

\section{References}

Bishop, R. F., Davidson, G. P., Holmes, I. H., and Ruck, B. J. (1974). Detection of a new virus by electron microscopy of faecal extracts from children with acute gastroenteritis. Lancet, 1, 149-151.

Bruce White, G. B., and Stancliffe, D. (1975). Letter: Viruses and gastroenteritis. Lancet, 2, 703.

Bryden, A. S., Davies, H. A., Hadley, R. E., Flewett, T. H., Morris, C. A., and Oliver, P. (1975). Rotavirus enteritis in the West Midlands during 1974. Lancet, 2, 241-243.

Davidson, G. P., Bishop, R. F., Townley, R. R. M., Holmes, I. H., and Ruck, B. J. (1975). Importance of a new virus in acute sporadic enteritis in children. Lancet, 1, 242246.

Flewett, T. H., Bryden, A. S., Davies, H., Woode, G. N., Bridger, J. C., and Derrick, J. M. (1974). Relation between viruses from acute gastroenteritis of children and newborn calves. Lancet, 2, 61-63.
Flewett, T. H., Bryden, A. S., Davies, H., and Morris, C. A. (1975). Epidemic viral enteritis in a long-stay childrens' ward. Lancet, 1, 4-5.

Fonteyne, J., Zissis, G., and Lambert, J. P. (1978). Letter: Recurrent rotavirus gastroenteritis. Lancet, 1, 983.

Kogasaka, R., Akihara, M., Agatsuma, Y., Horino, K., and Nakao, T. (1975). Viruses in acute infantile diarrhea. Journal of Clinical Pediatrics, 23, 266-271.

Madeley, C. R., Cosgrove, B. P., Bell, E. J., and Fallon, R. J. (1977). Stool viruses in babies in Glasgow. I. Hospital admissions with diarrhoea. Journal of Hygiene, 78, 261-273.

Rodriguez, W. J., Hyun Wha Kim, Brandt, C. D., Yolken, R. H., Arrobio, J. O., Kapikian, A. Z., Chanock, R. M., and Parrott, R. H. (1978). Letter: Sequential enteric illnesses associated with different rotavirus serotypes. Lancet, 2, 37.

Thouless, M. E., Bryden, A. S., and Flewett, T. H. (1978). Letter: Serotypes of human rotavirus. Lancet, 1, 39.

Whitelaw, A., Davies, H., and Parry, J. (1977). Letter: Electron microscopy of fatal adenovirus gastroenteritis. Lancet, 1, 361.

Zissis, G., and Lambert, J. P. (1978). Letter: Different serotypes of human rotaviruses. Lancet, 1, 38-39.

Correspondence to Dr S. Chiba, Department of Paediatrics, Sapporo Medical College, S1-W17, Chuo-ku, Sapporo 060, Japan.

\title{
Pathogenesis of oxytocin-induced neonatal hyperbilirubinaemia
}

\author{
SUNIT SINGHI AND MEHARBAN SINGH
}

Department of Paediatrics, All-India Institute of Medical Sciences, New Delhi

SUMMARY 100 term (gestation at least 37 weeks), vertex presenting, vaginally delivered, and fetomaternal blood-group-compatible neonates were studied to evaluate the pathogenesis of neonatal hyperbilirubinaemia induced by oxytocin. 50 infants were born after oxytocin infusion for augmentation of labour and the other 50 were delivered spontaneously. The babies born after oxytocin induction of labour attained significantly higher serum bilirubin levels at age $72 \pm 12$ hours than the controls. Infants born after oxytocin showed significant hyponatraemia, hypo-osmolality, and enhanced osmotic fragility of erythrocytes at birth. These biochemical and physiological alterations can be explained by the antidiuretic effects of oxytocin and concomitant administration of large quantities of electrolyte-free dextrose solutions used to administer it. Our observations suggest that cord serum sodium and/or osmolality should be estimated and infants with serum sodium $<125 \mathrm{mmol} / 1$ and/or osmolality $<260 \mathrm{mmol} / \mathrm{kg}$ should be considered for prophylactic administration of phenobarbitone.
The role of oxytocin in causing neonatal hyperbilirubinaemia is now generally accepted (Oski, 1975; Chew and Swann, 1977). However, the pathogenesis of such a hyperbilirubinaemia is still a matter of speculation. A relatively immature glucuronyl transferase system due to absence of the hormonal upsurge of normal labour (Sims and Neligan, 1975) and an enhanced placento-fetal transfusion due to oxytocin-induced uterine contractions, with resultant increase in red cell mass in neonates (Oski, 1975), have been suggested. To explain the pathogenesis of oxytocin-induced neonatal hyperbilirubinaemia, we tested the antidiuretic effect of oxytocin.

\section{Subjects and methods}

From September to November 1977, 100 term (gestation at least 37 weeks), vertex presenting, vaginally delivered, fetomaternal blood-groupcompatible neonates born at this hospital were studied. 50 of them were born after oxytocin infusion for induction or augmentation of labour (group 1), while the other 50 were delivered 